\title{
Supply Chain Management for Garments Industries Us- ing Blockchain in Bangladesh
}

\author{
Mahadi Hasan Miraz
}

School of technology Management and Logistics, $\mathrm{PhD}$, University Utara Malaysia

Malaysia.mahadimiraz1@gmail.com

\section{Mohamad Ghozali Hasan}

School of technology Management and Logistics, Senior Lecturer, University Utara Malaysia, Malaysia.ghozali@uum.edu.my

\section{Kamal Imran Sharif}

School of technology Management and Logistics, Senior Lecturer, University Utara Malaysia, Malaysia. kamalimran@uum.edu.my

\begin{abstract}
Bangladesh garments industry plays a significant role for Bangladesh economy. It helps millions of workers in Bangladesh. As difficulties to trade among nations have failed due to improved shipping systems, technology transfer and government cooperation, the industry has seen a rapid increase in globalization and struggle. The all Bangladesh apparels mills association and individuals needs to enhance the quality of its goods. However, the promises in the RMG can be comprehended only if the challenges in some areas like - organizations, compliances, workforces supply, dealers' performances, raw resources, political stability are tackled. In order to minimize the issues we need a proper supply chain using Blockchain.
\end{abstract}

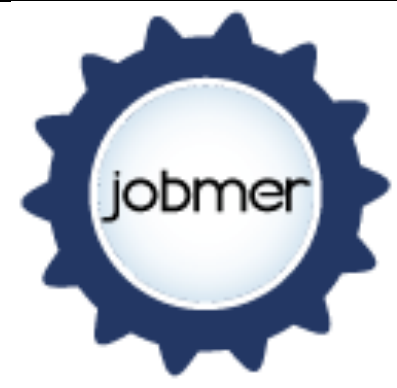

Journal of Business Management and Economic Research Vol.2, Issue.8, 2018 pp.13-20

Doi: 10.29226/TR1001.2018.54

Keywords: Supply Chain Management, Garments Industry

\subsection{Introduction}

Garments industries have been a tremendously significant part of Bangladesh's economy for a very long time for a number of reasons. Bangladesh is the world's second largest exporter of clothing after China. Ready-to-wear garments make up 80 percent of the country's \$24 billion in annual exports and 15 percent share of GDP (Anner, Bair \& Blasi, 2013). Consultancy firm McKinsey and Company has said Bangladesh could twice its garments exports in the next 10 years. In Asia, Bangladesh is the one of the largest exporter of garments products providing employment to a great share percent of 
the work force in the country. Presently, the garments industry accounts for $45 \%$ of all industrial employment in the country and contributes $5 \%$ of the total nationwide revenue (BMZ, 2014). Conversely, though the industry is one of the largest in Bangladesh and is still expanding, it faces massive challenges, principally because the country does not produce enough of the underdone materials necessary, uncomplimentary trade policies, and insufficient encouragements for development. Furthermore, Bangladesh's clothes industry depend on heavily on imports, and the country does not earn as much foreign exchange from its apparels industry as it should (BTE, 2016). Due to growing demand of sustainable apparel design, environmental changes, market struggle, changeable consumer demand, market trends of variety, short product life cycles and low blocks of entry the garments and apparel industry is one of the most highly competitive industrial sectors in the world (BTMC, 2012; Bangladesh Textile Journal, 2011).

\subsection{Garments Industry in Bangladesh}

Industrial Revolution in the eighteenth century, East Bengal was self-sufficient in textiles. Its people produced Muslin, Jamdani, and various cotton and silk fabrics. These were all well regarded even beyond the region as they were manufactured by very skilled craftsmen (Samaddar, 2016). This eventually led to a great decline in the number of Bengali workers skilled enough to produce such high quality fabrics. According to popularly held beliefs, as the region's spinners and weavers meant competition for their emerging garments industry, the British imperialists responded by trying to force the artisans to stop production. Bangladesh is no more developing countries in the world (Ministry of Finance, 2011). It has been stated as lower Middle Income Country by the World Bank on 01 July 2015 (BTE, 2016). This is absolute on the base of per capita income which is at present 1340 US dollar. It is predictable that Bangladesh can be advanced as middle income country with in 2021 if it can continue its development at present speed (Baral, 2010). In this situation it needs to progress not only in financial sector but also in social and human expansion sector (Akhi, 2017). Readymade garment sector is major contributor of the economy of Bangladesh (Alam \& Azim, 2017). RMG sector is the largest export earning source of our country (Akram, 2015).

\subsection{Garments industries and Blockchain technology}

Blockchain technology applications have the potential to transform our current use of garments industries and the associated hardware and so ware infrastructure (Akhi, 2017). Underling technology and associated crypto currency with its decentralized architecture suggests a range of applications that can, we argue, bring cost savings and egarments industries versus traditional legacy systems currently in use in garments industries (Seebacher \& Schüritz, 2017). We suggest that there are numerous applications 
that can be implemented in large garments industries for garments worker management system (GWMS) using blockchain technology (Crowe, 2017).

The fundamental promise of the blockchain is the underlying Information Technology (IT) architecture and its 'unbreakable' chain of data entries that allow for secure and open transactions (Crosby, Pattanayak, Verma \& Kalyanaraman, 2016). Decentralized and distributed database of a blockchain that contains data allows for an auditable and distributed ledger that allows all to see every transaction (Earley, 2017). Open source attributes of the blockchain make the technology a natural for the requirements associated with the complexities of transaction laden systems associated with health information technology in the public and private sector (Seebacher \& Schüritz, 2017).

\subsection{Problem statement}

There is little management system in garments industries. They are not really exposed and inactive in real world. However it slightly reduces the difficulties of management worker facility and lightly reduces the overall production cost. In addition this facility is very is very inactive in diverse operation. Furthermore it is not effective and not appropriate for real world. It is time to initiate new working management for garments industries for further improvement.

\subsection{Research Question}

1. What are the attributes and requirements needed to develop an effective garments worker management system (GWMS) using Blockchain technology?

2. How to develop a GWMS using Blockchain

3. How the GWMS system be evaluated

\subsection{Research objectives}

1. To identify the attributes and requirements needed to develop an effective garments worker management system (GWMS) using Blockchain technology?

2. To develop the GWMS using Blockchain

3. To evaluate the GWMS performance

\subsection{Scope of the study}

The scope of the study covers the few garments industries in Dhaka city. The researcher examined the limited garments and identified the challenges to help Dhaka garments 
management authority to expand the existing garments sector by transforming the garments worker management system.

\subsection{Research Significance}

This thesis introduces very new collaborative research on Garments working management system using block chain technology. In addition, we argue that the potential cost savings would be significant versus current costs and ongoing system maintenance of existing legacy IT systems. Blockchain is relatively easier to program and to implement system wide changes in comparison to changes made to legacy IT systems.

\subsection{Literature Review}

Garments workers (GW) play an important role in the development of garments industries (GI) in Bangladesh. The GW can enhance the growth of the economy if garments worker management system is done using blockchain. However, GI operators face a lack of knowledge on technology and systematic management. This chapter attempts to review some earlier works that have been done. These earlier works are in relation to the objectives to innovate garments worker managements (GWM) application to handle Garments industries.

\subsection{Garments Worker Managements}

Garments worker management (GWM) is an important part of garments industries and it is defined electronic garments worker management system (GWMS). However there are many way to operate GWM.

\section{Research Methodology}

This research combines qualitative and quantitative approaches. The data required in this research is the criteria for developing good and effective Garments worker management (GWM). In addition, for secondary data were collected by reviewing the literature. Furthermore, For primary data collected via participatory action research workshop conducted for the garments operators in the capital city of Bangladesh. All the primary and secondary data obtained were used to develop the GWM using Blockchain technology.

\section{Discussion on Technology Description and Application}

The initiation of blockchain technology can trace its early periods to formation of Bitcoin as a digital crypto currency (Gartner, 2016.). Though, the rise of digital only currencies in current years has taken the attention of the economic industry, the public, 
and regulators it remains largely unknown to the general public. The modern technology that aided to launch Bitcoin or 'blockchain' is of specific interest and possible use to a extensive range of manufacturing, including garments-care since of the open source and decentralized nature of the technology (Crowe, 2017).

\subsection{Blockchain in Healthcare}

Blockchain has prospective to progress healthcare in a number of advanced ways. Some of those instances include a Master Patient Identifier (MPI), autonomous automatic adjudication and interoperability (Accenture, 2016). MPI's offers a single person identifier that can follow the patient in various situations, enabling a more unified and scalable health distribution across the continuum of care providers (as well as possibly beyond healthcare where data would also of relevance) (Renita, 2017). Autonomous automatic settlement would make simpler and lead to e-education how claims or other healthcare dealings are processed between parties. Essentially, blockchain could lead to elimination of the third party thus creating a more e cient process. E-process would use keen contracts across parties that would enable automatic adjudication of claims. Enhancing claim settlement in health care has the benefit of decrease in the incidence of claim fraud that is presently established (Culver, 2016.). All players in healthcare, from providers to payers, would benefit from this reduction in fraud.

\subsection{Fraud detection}

Fraud detection and extenuation is progressively becoming a policy issue around the globe. Current suggest that the deployment of a blockchain application that utilizes a smart contract and verify able ledger of all service and payment activities could reduce fraud and overpayment that is prevalent in the current fraud detection(Tapscot \& Tapscott, 2016). Blockchain could also improve interoperability across systems and organizations. is crucial for progress in our current health ecosystem which consists of a plethora of disparate IT legacy systems that have been amassed over the years and that do not communicate well with each other (Peck, 2015). Blockchain would deliver the capability to replace these disparate systems with a single system that offers interoperability. With the use of smart agreements and fully auditable history, Blockchain would enable peer-to-peer interoperability among members within transactions (PWC, 2015). In addition to offering interoperability, blockchain dealings would also have the benefit of being cryptographically and irreversible thus safeguarding privacy from corner to corner parties.

\subsection{E-federal government in}

E-federal government can also advantage from the development in blockchain with more rationalized transactions in the supply chain. For example, one of the issues facing Medicaid recipients is high churn due to changing economic qualifications. Blockchain can be helpful to maintain a recipient's individuality as they pivot between di erent gov- 
ernments systems in a more seamless way (Swan, 2017). This is would be particularly appreciated if account based plans from the private sector are applied as an option for Medicaid recipients (with hope of reduction in costs and better outcomes (Wons \& Mike, 2017). Other government programs would likewise advantage from a more efficient delivery of care across all players within the supply chain, including with private prescription plans.

\section{Records Management}

The adoption of automated records systems has been a 'holy grail' for the education industry Current industry and government reports propose that procedure of electronic business record standards outlined by the 2009 law that has funded much of the industry growth is lagging behind with a good deal of variation in provider adoption rates (Swan, 2017). That facts take on added significant as the Centers for business handle and modern business Services (MBS) begin to tie future funding to provider adoption and 'meaningful use' attestation by providers (Wons \& Mike, 2017).

\section{Benefits Administration}

Blockchain technology has the capability to abridge and decrease the cost of services management and administration (Qlnes, 2016). As benefits design, enrolment, beneficiary engagement and provider payment systems have evolved overtime there are the unavoidable and expected problems related with the countless of business information technology systems designed to work together (Kim, 2016). Interoperability has developed a key apprehension and challenge in the development and deployment of the health IT infrastructure. We suggest that the use of blockchain application can assist in dealing with the challenges and allow for numerous systems to work in greater efficiency (Christidis, 2016). Benefits administration includes the use of disparate systems that are deliberate to gather and process data from many sources such as: health care, retail market and garments industries etc.

\section{Conclusion}

The merits of blockchain are clear, but with any new technology there are questions about correctness and capability. In this research we endeavor to answer questions about the technology adaption through Blockchain, issues of interoperability and special applications connected to the garments industry and related costs. We also talk some of the confidentiality and data safety doubts associated with various departments of garments industries that are inherent in any health IT system. Lastly, we also inspect the strategy implications of organizing blockchain technology and propose additional areas of research. 


\section{References}

Anner, M., Bair, J., and Blasi, J. (2013). Toward joint liability in global supply chains: Addressing the root causes of labor violations in international subcontracting networks. Comparative Labor Law \& Policy Journal, 35(1), 1-44.

Alam \& Azim (2017) Social Compliance in Ready-Made Garment Industry in Bangladesh: Challenges for HR Personnel. J Appl Environ Biol Sci 7: 8-18.

Samaddar KK (2016) Occupational Health And Safety Management In RMG Sector Of Bangladesh. International Journal of Scientific \& Technology Research 5: 176-193.

BMZ (2014). Nachhaltige Textilien - was tut die deutsche Entwicklungspolitik. Redaktion: Referat Öffentlichkeitsarbeit, digitale Kommunikation und Besucherdienst, Berlin.

BTE (2016). Statistikreport 2016 - Textileinzelhandel. Bundesverband des Deutschen Textileinzelhandels.

Bangladesh Textile Mills Corporation (BTMC) (2012) (Various Issues) Annual Report (20052012)

Baral (2010) Comparative study of compliant \& non-compliant RMG factories in Bangladesh. International Journal of Engineering \& Technology 10: 3-27.

Akhi (2017) An overview of Bangladesh RMG 2016.

Ministry of Finance (2011). Bangladesh, Government of Bangladesh Economic Survey.

Crosby, M.; Pattanayak, P.; Verma, S.; Kalyanaraman, V. Blockchain technology: Beyond bitcoin. Appl. Innov. 2016, 2, 6-10.

Earley (2017) Supply Chain Transparency: Forging Better Relationships with Suppliers. Available online: https://www.theguardian.com/sustainable-business/supply-chaintransparency-relationships-suppliers (accessed on 2 September 2017).

Seebacher, S.; Schüritz (2017). Blockchain Technology as an Enabler of Service Systems: A Structured Literature Review. In Proceedings of the International Conference on Exploring Services Science, Rome, Italy, 24-26 May 2017; pp. 12-23.

Gartner (2016). Available online: https://www.gartner. com/doc/3278917/bitcoin-blockchainmagic-myths (accessed on 6 September 2017).

Crowe (2017) There Is a 'Game Changer' Technology on Wall Street and People Keep Confusing It with Bitcoin. Available online: http://www.businessinsider.com/what-isblockchain-2016-3 (accessed on 7 September 2017).

Accenture (2016). "Blockchain: Securing a New Health Interoperability Experience"Blockchain ONC Challenge.

https://oncprojectracking.healthit.gov/wiki/download/attachments/14582699/2-49accentre onc blockchain challenge response august 8 final.pdf?

version $=1 \&$ modificationDate $=1472657006000 \&$ api $=$ v2 
Culver, Kyle (2016). "Blockchain Technologies: A Whitepaper Discussing How the Claims Process Can Be Improved" Blockchain ONC Challenge. https://oncprojectracking.healthit.gov/wiki/download/attachments/14582699/3-47- whitepaperblockchainforclaims_v10.pdf?version $=1 \&$ modificationDate $=1472657193000 \&$ api $=$ v2 Das.

Renita (2017). "Does Blockchain Have A Place In Healthcare?" Forbes. https://www.forbes.com/sites/reenitadas/2017/05/08/does-blockchain-have-a-place-inhealthcare/\#178115f1c31e

Peck M (2015) "The Future of the Web Looks a Lot Like Bitcoin," Spectrum IEEE (1 July). http://spectrum.ieee.org/ computing/networks/the-future-of-the-web-looks-a-lot-likebitcoin PwC (2015) Information security breaches survey.

PWC (2015). The PWC in association with Info Security Europe. https://www.pwc.co.uk/assets/pdf/2015-isbs-technical-report-blue-03.pdf. Accessed 1 Nov 2016

Swan (2017) "Bitcoin Protocols 1.0 and 2.0 Explained in the Series: Blockchain: The Information Technology of the Future." Institute for Blockchain Studies. http://blockchainstudies.org/index.html. Presentation accessed on 3/28/2017 from https://www.slideshare.net/ lablogga/bitcoin-protocols-10-and-20-explained-in-the-seriesblockchain-the-information-technology-of-the-future.

Wons, Mike (2017) "Digital Transformation in Government, The Illinois Blockchain Initiative." NASCIO Enterprise Architecture \& Governance Committee Monthly Conference Call, March 9, 2017. Presentation and discussion by Mr. Mike Wons, Chief Technology Officer, State of Illinois.

Tapscott \& Tapscott (2016) "The Impact of the Blockchain Goes Beyond Financial Services," Harvard Business Review. https://hbr.org/2016/05/the-impact-of-the-blockchain-goesbeyond-financial-service.

Qlnes (2016). Beyond bitcoin enabling smart government using blockchain technology. In Proceedings of the International Conference on Electronic Government and the Information Systems Perspective, Porto, Portugal, 5-8 September 2016; pp. 253-264.

Kim \& Laskowski (2016). Towards an Ontology-Driven Blockchain Design for Supply Chain Provenance; SSRN: Rochester, NY, USA, 2016.

Christidis \& Devetsikiotis (2016). Blockchains and Smart Contracts for the Internet of Things. IEEE Access 2016, 4, 2292-2303 